\title{
Conduction Disorders in Continuous Versus Interrupted Suturing Technique in Ventricular Septal Defect Surgical Repair
}

\author{
Maziar Gholampour-Dehaki ${ }^{1}$; Asghar Zareh ${ }^{1}$; Solmaz Babaki ${ }^{1,2}$; Hoda Javadikasgari ${ }^{1,3, *}$ \\ ${ }^{1}$ Heart Valve Disease Research Center, Rajaie Cardiovascular Medical and Research Center, Iran University of Medical Sciences, Tehran, IR Iran \\ ${ }^{2}$ Department of Cardiology, Ludmillenstift Hospital, Ludmillenstraße, Meppen, Germany \\ 3 Department of Thoracic and Cardiovascular Surgery, Cleveland Clinic Foundation, Cleveland, Ohio, USA \\ *Corresponding author: Hoda Javadikasgari, Heart Valve Disease Research Center, Rajaie Cardiovascular Medical and Research Center, Vali-Asr St., Niayesh Blvd, P. O. Box: 1996911151, \\ Tehran, IR Iran. Tel:+1-6822192494, E-mail: Hoda.Javadi.K@gmail.com
}

Received: May 12, 2015; Revised: June 22, 2015; Accepted: July 4, 2015

\begin{abstract}
Background: Ventricular septal defects (VSD) is one of the most frequent congenital cardiac malformations and cardiac conduction disorders are still one of the serious postoperative complications in this surgery.

Objectives: This study aimed to compare the incidence of conduction disorders with the use of continuous compared to interrupted suturing techniques in VSD surgical repair.

Patients and Methods: Previously recorded data of 231 patients who underwent surgical closure of VSD between January 2009 and January 2012 at the Rajaie cardiovascular medical and research center were retrospectively reviewed. VSD surgical repair was performed using continues suturing technique in group A patients $(n=163,70.6 \%)$ and interrupted suturing technique in group B patients $(n=68$, 29.4\%).

Results:The most common concomitantcongenital anomaly was Tetralogy of Fallot(27.3\%).Twenty-four(10.4\%)patients had intraoperative cardiac arrhythmia, including 19 (8.2\%) transient and 5 (2.2\%) permanent arrhythmia. During their ICU stay, ventricular arrhythmia and complete heart block were observed in $34(14.7 \%)$ and 5 patients (2.2\%), respectively. At the time of the last follow-up, incomplete right bundle branch block (RBBB), complete RBBB, RBBB with left anterior hemi-block, and complete heart block were identified in 84 (36.4\%), $42(18.2 \%), 29$ (12.6\%), and 5 patients (2.2\%), respectively. The results revealed that group A patients were most likely to have had cardiac arrhythmias during their ICU stay and at the time of last follow-up $(\mathrm{P}<0.001)$, while the intraoperative incidence of cardiac arrhythmia during surgery was not statistically significant between the two groups $(\mathrm{P}=0.06)$.

Conclusions: In the absence of any statistical differences in the other risk factors between the two groups, the difference in the incidence of conduction disorders can be attributed to the type of suturing used during the procedure.
\end{abstract}

Keywords: Ventricular Septal Defect Repair; Defect; Cardiac Arrhythmia

\section{Background}

Ventricular septal defects (VSDs) are the most frequent congenital cardiac malformations. One of the serious post-surgical complications remains the development of a complete heart block. Closure of VSD is usually achieved by anchoring a patch using either a continuous or an interrupted suture. During this maneuver, traction and tension are needed in order to obtain good surgical exposure. The conduction system, specifically the bundle of His and its branches, is usually closely related to some part of the border of the defect, and is at risk for damage during the insertion of the individual stitches. If heart block occurs during or after the procedure, it is most often an indication for permanent pacemaker insertion. This is performed through partial or complete sternotomy, which has been demonstrated to increase the risk of late death in patients with postsurgical complete heart block (1).

Large single center studies report a $0 \%$ to $3 \%$ incidence of atrioventricular (AV) block after the operative repair of VSDs $(2,3)$. Recent studies have reported a $2 \%$ to $3.6 \%$ incidence of AV block requiring immediate and late permanent pacemaker placement after transcatheter device closure of perimembranous $\operatorname{VSD}(4,5)$.

\section{Objectives}

The aim of this study was to compare the incidence of AV block between the continuous and interrupted suture groups, respectively.

\section{Patients and Methods}

Patients who underwent surgical closure of VSD between January 2009 and January 2012 were identified from our databases at the Rajaie cardiovascular, medical and research center. Patients who were $\leq 18$ years old at the time of surgery were included in this study while those with an atrioventricular canal were excluded from

Copyright ( ) 2016, Rajaie Cardiovascular Medical and Research Center, Iran University of Medical Sciences. This is an open-access article distributed under the terms of the Creative Commons Attribution-NonCommercial 4.0 International License (http://creativecommons.org/licenses/by-nc/4.0/) which permits copy and redistribute the material just in noncommercial usages, provided the original work is properly cited. 
participation. The local ethics committee, faculty of medicine, Iran University of Medical Sciences, Tehran, Iran approved the protocol for this study.

A total of 239 patients underwent congenital VSD repair between January 2009 and January 2012. Data from 8 patients were excluded due to either atrioventricular canal or incomplete information. Details about the patients' past medical and surgical history, intracardiac hemodynamics, ventricular function, associated cardiac anomalies, New York heart association functional class, surgical indication and postoperative complications, and patient outcomes, were retrospectively reviewed from clinical notes, surgical protocols, and imaging study reports, respectively.

\subsection{Surgical Technique}

Standard cardiopulmonary bypass with cold potassium and blood cardioplegic solution was used in all surgeries. The use of the suture or patch closing technique, the approach to the ventricular septum, and the type of suturing that was used, were noted. The largest VSD diameter at surgical inspection was used for determining the defect size. The diameter reported in preoperative echocardiography was used when the VSD diameter was not reported in the operative notes.

\subsection{Statistical Analysis}

Multivariable logistic regression was performed in order to develop a parsimonious model for identifying factors that were associated with separated suture techniques. A directed stepwise approach using the criteria of $\mathrm{P} \leq 0.05$ for retention of variables was utilized for the initial model. The factors that demonstrated the greatest association with the separated suture techniques included the preoperative treatment (Odds ratio $=0.32, \mathrm{P}=0.013$ ) and positional anomaly (Odds ratio $=0.005, \mathrm{P}<0.0001$ ) which were not statistically different between the two groups (Tables 1 and 2).

Table 1. Comparison of the Continuous Demographic Characteristics of the Patients in the Two Suture Groups ${ }^{\text {a }}$

\begin{tabular}{|c|c|c|c|c|}
\hline Variables & Total & Continuous & Interrupted & P Value \\
\hline Age, mo & $50.53 \pm 38.38$ & $49.42 \pm 36.46$ & $53.25 \pm 42.92$ & 0.98 \\
\hline Height, cm & $98.03 \pm 22.73$ & $97.37 \pm 22.51$ & $99.64 \pm 23.36$ & 0.89 \\
\hline Weight, Kg & $15.40 \pm 10.63$ & $14.91 \pm 8.69$ & $16.59 \pm 14.29$ & 0.69 \\
\hline BSA & $0.61 \pm 0.24$ & $0.61 \pm 0.21$ & $0.63 \pm 0.29$ & 0.68 \\
\hline Age of PA banding, mo & $2.26 \pm 4.57$ & $2.55 \pm 5.05$ & $1.56 \pm 3.06$ & 0.15 \\
\hline Weight of PA banding, Kg & $1.89 \pm 3.07$ & $2.11 \pm 3.26$ & $1.37 \pm 2.49$ & 0.13 \\
\hline Preoperative LVEF & $61.60 \pm 6.32$ & $61.54 \pm 6.94$ & $61.74 \pm 4.51$ & 0.82 \\
\hline Postoperative LVEF & $60.35 \pm 5.24$ & $60.30 \pm 5.50$ & $60.54 \pm 4.35$ & 0.84 \\
\hline Preoperative LV-RV gradient & $26.23 \pm 25.17$ & $25.81 \pm 27.39$ & $27.27 \pm 18.86$ & 0.28 \\
\hline Preoperative QP/QS & $2.11 \pm 0.82$ & $2.05 \pm 0.89$ & $2.24 \pm 0.65$ & 0.70 \\
\hline VSD/BSA & $1.91 \pm 0.98$ & $1.90 \pm 1.07$ & $1.92 \pm 0.75$ & 0.29 \\
\hline Pump time, min & $110 \pm 42.42$ & $93.01 \pm 37.62$ & $118.15 \pm 65.17$ & 0.001 \\
\hline ACC time, min & $67.50 \pm 38.89$ & $58.52 \pm 35.24$ & $66.49 \pm 23.41$ & 0.001 \\
\hline Temp & $2.26 \pm 0.45$ & $2.30 \pm 0.48$ & $2.17 \pm 0.37$ & 0.07 \\
\hline ICU stay, d & $2.85 \pm 1.18$ & $2.88 \pm 1.16$ & $2.78 \pm 1.24$ & 0.175 \\
\hline Intubation duration, $d$ & $1.20 \pm 0.49$ & $1.22 \pm 0.49$ & $1.17 \pm 0.49$ & 0.38 \\
\hline PR interval, cm & $0.11 \pm 0.07$ & $0.11 \pm 0.06$ & $0.11 \pm 0.09$ & 0.001 \\
\hline QRS duration, $\mathrm{cm}$ & $0.13 \pm 0.05$ & $0.14 \pm 0.06$ & $0.12 \pm 0.03$ & 0.001 \\
\hline Follow-Up, mo & $13.28 \pm 12.93$ & $13.64 \pm 14.04$ & $12.26 \pm 9.13$ & 0.84 \\
\hline
\end{tabular}

${ }^{\mathrm{a}}$ The values are presented as mean $\pm \mathrm{SD}$. 
Gholampour-Dehaki M et al.

\begin{tabular}{|c|c|c|c|c|}
\hline Variables & Total & Continuous & Interrupted & Pvalue \\
\hline Gender & & & & 0.14 \\
\hline Male & $130(56.3)$ & $90(55.2)$ & $40(58.8)$ & \\
\hline Female & $101(43.7)$ & $73(44.8)$ & $28(41.2)$ & \\
\hline Preoperative medical treatment & $162(70.1)$ & $108(33.6)$ & $54(79.4)$ & 0.058 \\
\hline PA banding & $70(30.3)$ & $55(33.7)$ & $15(22.1)$ & 0.086 \\
\hline PDA & $55(22.1)$ & $35(21.5)$ & $20(29.4)$ & 0.73 \\
\hline Coarctation of the aorta & $3(1.3)$ & $2(1.2)$ & $1(1.5)$ & 0.88 \\
\hline Congenital AS & $4(1.7)$ & $1(0.6)$ & $3(4.4)$ & 0.04 \\
\hline Subvalvular stenosis & $10(4.3)$ & $4(2.5)$ & $6(8.8)$ & 0.068 \\
\hline Congenital MS & $1(0.4)$ & $0(0)$ & $1(1.5)$ & 0.12 \\
\hline Congenital MR & $8(3.5)$ & $6(3.7)$ & $2(2.9)$ & 0.78 \\
\hline Absence of PA & $2(0.9)$ & $2(1.2)$ & 0 & 0.36 \\
\hline Stenosis of PA & $31(13.4)$ & $20(12.3)$ & $11(16.2)$ & 0.52 \\
\hline ASD & $49(21.2)$ & $38(23.3)$ & $11(16.2)$ & 0.29 \\
\hline Positional Anomaly & $9(3.9)$ & $4(2.5)$ & $5(7.4)$ & 0.08 \\
\hline TOF & $63(27.3)$ & $45(27.6)$ & $18(26.5)$ & 0.86 \\
\hline Malposition of the great arteries & $10(4.3)$ & $10(6.1)$ & $0 .(0)$ & 0.04 \\
\hline Truncus arteriosus & $2(0.9)$ & $2(1.2)$ & $0(0)$ & 0.36 \\
\hline Tricuspid atresia & $0(0)$ & $0(0)$ & $0(0)$ & \\
\hline Sinus of valsalva aneurysm & $0(0)$ & $0(0)$ & $0(0)$ & \\
\hline Interrupted aortic arch & $0(0)$ & $0(0)$ & $0(0)$ & \\
\hline Dexterocardia & $1(0.4)$ & $1(0.6)$ & 0 & 0.52 \\
\hline Situs inversus totalis & $0(0)$ & $0(0)$ & $0(0)$ & - \\
\hline Type of VSD & & & & 0.8 \\
\hline Perimembranous & $194(84)$ & $135(58.4)$ & $59(86.80)$ & \\
\hline \multicolumn{5}{|l|}{ Muscular } \\
\hline Anterior & $4(1.7)$ & $3(1.8)$ & $1(1.5)$ & \\
\hline Apical & $2(0.9)$ & $2(1.2)$ & 0 & \\
\hline Trabecular & $4(1.7)$ & $4(2.5)$ & 0 & \\
\hline Inlet & $14(6)$ & $11(6.7)$ & $3(4.4)$ & \\
\hline Doubly committed & $7(3)$ & $5(3.1)$ & $2(2.9)$ & \\
\hline Subarterial & $3(1.3)$ & $2(1.2)$ & $1(1.5)$ & \\
\hline Inlet & $4(1.7)$ & $1(0.6)$ & $3(4.4)$ & \\
\hline TR & & & & 0.10 \\
\hline Mild & $104(45)$ & $77(47.2)$ & $27(39.7)$ & \\
\hline Moderate & $33(14.3)$ & $16(9.8)$ & $17(25)$ & \\
\hline Severe & $3(1.3)$ & $3(1.8)$ & 0 & \\
\hline AI & & & & 0.26 \\
\hline
\end{tabular}


Gholampour-Dehaki M et al.

\begin{tabular}{|c|c|c|c|c|}
\hline Mild & $11(4.8)$ & $10(6.1)$ & $1(1.5)$ & \\
\hline Moderate & $9(3.9)$ & $6(3.7)$ & $3(4.4)$ & \\
\hline Severe & $3(1.3)$ & $3(1.8)$ & 0 & \\
\hline VSD Diameter & & & & 0.46 \\
\hline Small & $20(8.7)$ & $13(8)$ & $7(10.3)$ & \\
\hline Moderate & $34(14.7)$ & $23(14.1)$ & $11(16.2)$ & \\
\hline Large & $177(77.6)$ & $127(77.9)$ & $50(73.5)$ & \\
\hline VSD Shunt & & & & 0.46 \\
\hline Left to right & $185(80.1)$ & $128(78.5)$ & $57(83.8)$ & \\
\hline Right to left & $24(10.4)$ & $19(11.7)$ & $5(7.4)$ & \\
\hline Both & $22(9.5)$ & $15(9.2)$ & $7(10.3)$ & \\
\hline Technique & & & & 0.03 \\
\hline Atrial & 201(87) & $135(82.8)$ & $66(97.1)$ & \\
\hline Ventricular & $26(11.3)$ & $26(16)$ & 0 & \\
\hline Aorta & $4(1.7)$ & $2(1.2)$ & $2(2.9)$ & \\
\hline \multicolumn{5}{|l|}{ Suture type } \\
\hline Continuous & $163(70.6)$ & & & \\
\hline Interrupted & $68(29.4)$ & & & \\
\hline Patch type & & & & 0.03 \\
\hline Pericard & $15(6.5)$ & $12(7.4)$ & $3(4.4)$ & \\
\hline Goretex & $200(86.5)$ & $140(86)$ & $60(88.2)$ & \\
\hline Dacron & $16(7)$ & $11(6.6)$ & $5(7.4)$ & \\
\hline Aortic repair & & & & 0.63 \\
\hline Direct & $7(3)$ & $5(3.1)$ & $2(2.9)$ & \\
\hline Patch & $9(3.9)$ & $7(4.3)$ & $2(2.9)$ & \\
\hline Tricuspid repair & $42(18.2)$ & $19(11.7)$ & $23(33.8)$ & $<0.001$ \\
\hline PA debanding & & & & 0.19 \\
\hline Direct & 39 (16.9) & $30(18.4)$ & $9(13.2)$ & \\
\hline With patch & $15(6.5)$ & $12(7.4)$ & $3(4.4)$ & \\
\hline Inotrope dose & & & & 0.59 \\
\hline $\operatorname{Low}(<0.02)$ & $121(52.4)$ & $83(50.9)$ & $38(55.9)$ & \\
\hline Mod dose $(0.05-0.1)$ & $32(13.9)$ & $27(16.6)$ & $5(7.4)$ & \\
\hline $\operatorname{High}(>0.2)$ & $4(1.7)$ & $4(2.5)$ & 0 & \\
\hline None & $74(32)$ & $49(30.1)$ & $25(36.8)$ & \\
\hline Reoperation & $9(3.9)$ & $9(5.5)$ & 0 & 0.049 \\
\hline Defective growth & $4(1.7)$ & $3(1.8)$ & $1(1.2)$ & 0.84 \\
\hline Residual Shunt & & & & $<0.001$ \\
\hline Small (1 - 2.3) & $118(51.1)$ & $101(62)$ & $17(25)$ & \\
\hline Moderate & $10(4.3)$ & $10(6.1)$ & 0 & \\
\hline Severe & 0 & 0 & 0 & \\
\hline
\end{tabular}


Gholampour-Dehaki M et al.

Residual PS

0.81

\begin{tabular}{|c|c|c|c|c|}
\hline Mild & $48(20.8)$ & $33(19.6)$ & $15(22.1)$ & \\
\hline Moderate & $2(0.9)$ & $1(0.6)$ & $1(1.2)$ & \\
\hline Severe & $1(0.4)$ & $1(0.6)$ & 0 & \\
\hline Post-operative TR & & & & 0.45 \\
\hline Mild & $132(57.1)$ & $89(54.6)$ & $43(63.2)$ & \\
\hline Moderate & $19(8.2)$ & $18(11)$ & $1(1.2)$ & \\
\hline Severe & $1(0.4)$ & $1(0.6)$ & 0 & \\
\hline Postoperative AI & & & & 0.26 \\
\hline Mild & $74(32)$ & $48(29.4)$ & $26(38.2)$ & \\
\hline Moderate & $3(1.3)$ & $3(1.8)$ & 0 & \\
\hline Severe & $1(0.4)$ & $1(0.6)$ & 0 & \\
\hline Rhythm (OR) & & & & 0.06 \\
\hline Sinus & $207(89.6)$ & $141(86.5)$ & $66(97.1)$ & \\
\hline Transient pace maker & $19(8.2)$ & $17(10.5)$ & $2(2.9)$ & \\
\hline Permanent pace maker & $5(2.2)$ & $5(3.0)$ & 0 & \\
\hline Rhythm (ICU) & & & & $<0.001$ \\
\hline Sinus & $192(83.1)$ & $126(77.3)$ & $66(97.1)$ & \\
\hline $\mathrm{CHB}$ & $5(2.2)$ & $5(3.0)$ & 0 & \\
\hline AVB & $34(14.7)$ & $32(19.7)$ & $2(2.9)$ & \\
\hline Rhythm (Follow-up) & & & & $<0.001$ \\
\hline Sinus & $71(30.6)$ & $25(15.3)$ & $46(67.6)$ & \\
\hline Incomplete RBBB & $84(36.4)$ & $69(42.3)$ & $15(22.1)$ & \\
\hline Complete RBBB & $42(18.2)$ & $39(24)$ & $3(4.4)$ & \\
\hline RBBB + left ant Hemi-block & $29(12.6)$ & $25(15.4)$ & $4(5.9)$ & \\
\hline $\mathrm{CHB}$ & $5(2.2)$ & $5(3.0)$ & 0 & \\
\hline Complication & & & & 0.33 \\
\hline Bleeding & $5(2.2)$ & $5(3.1)$ & 0 & \\
\hline PH crisis & $2(0.9)$ & $2(1.2)$ & 0 & \\
\hline Death & $1(0.4)$ & $1(0.6)$ & 0 & 0.52 \\
\hline
\end{tabular}

a The values are presented as No. (\%).

Furthermore, stepwise logistic regression models were used to find multivariate predictors for postoperative cardiac arrhythmia in order to detect confounding variables. The multivariable model included all the significant variables that were identified during univariate analysis $(\mathrm{P}<0.05)$. Model selection was performed using the stepwise method (backward and forward methods resulted in the same model). The factors that were most associated with postoperative cardiac arrhythmia are exhibited in Table 3. There were no significant differences in the confounding variables between the two suture type groups. Therefore, the two groups were already well matched and did not require propensity match analysis (6).

Categorical variables were reported as frequency and percentage while continuous variables were reported as the mean with standard deviation, respectively. Categorical baseline characteristics and outcomes were compared between groups using the chi-square or Fisher exact tests (where appropriate), while continuous variables were compared using analysis of variance or Kruskal-Wallis tests (where appropriate). All statistical tests were 2 sided with the alpha level set at 0.05 for statistical significance. 
Table 3. Comparison of The Variables Identified By Multivariate Logistic Regression According To The Timing of Arrhythmia Occurrence (Operating Room, Icu, After Discharge)

\begin{tabular}{|c|c|c|c|}
\hline Variables & $\begin{array}{c}\text { Cardiac Arrhythmia } \\
\text { (Operating Room) }\end{array}$ & $\begin{array}{c}\text { Cardiac Arrhythmia } \\
\text { (ICU) }\end{array}$ & $\begin{array}{c}\text { Cardiac Arrhythmia } \\
\text { (Discharge) }\end{array}$ \\
\hline Age & - & & - \\
\hline Gender & & - & \\
\hline Height & - & & - \\
\hline Weight & - & & - \\
\hline Body surface area (BSA) & - & & - \\
\hline Preoperative treatment & & - & - \\
\hline Congenital mitral regurgitation & & & - \\
\hline Absence of pulmonary artery & - & - & \\
\hline Atrial septal defect & & - & \\
\hline Position anomaly & & - & \\
\hline Type of ventricular septal defect (VSD) & - & & \\
\hline VSD/BSA & - & & \\
\hline Suture technique & & & - \\
\hline Aortic repair & & - & \\
\hline Inotrope use & - & & \\
\hline ICU stay & - & & - \\
\hline Intubation period & - & & - \\
\hline Postoperative Tricuspid regurgitation & & - & \\
\hline Residual VSD shunt & & & - \\
\hline PR Interval & & - & - \\
\hline QRS duration & - & - & - \\
\hline
\end{tabular}

\section{Results}

Two hundred and thirty-one patients, including 130 (56.3\%) male subjects, with a mean age of $50.53 \pm 38.38$ months, were included in the study. The mean followup time was $13.28 \pm 12.93$ months. The most common concomitant congenital anomaly was Tetralogy of Fallot (27.3\%) followed by persistent ductus arteriosus (22.1\%), atrial septal defect (21.2\%), and stenosis of the pulmonary artery (13.4\%). The continues variables are described in Table 1, while categorical variables are exhibited in Table 2. One hundred and sixty-three (70.6\%) and 68 (29.4\%) patients with VSD underwent surgical repair using the continuous (group A) and interrupted (group B) suture types, respectively. The patients in group $B$ had longer pump and aortic cross clamp times $(\mathrm{P}<0.001$ and $\mathrm{P}=$ 0.001 , respectively) while group A patients had longer PRIntervals and QRS durations at the time of discharge ( $P$ $=0.001$ and $\mathrm{P}<0.001$, respectively). However, the differences in the other risk factors for postoperative cardiac arrhythmia (Table 3) were not statistically significant between the two groups (Table 1 and Table 2). Twenty-four $(10.4 \%)$ patients had intraoperative cardiac arrhythmias, 19 (8.2\%) had transient and 5 (2.2\%) had permanent cardiac arrhythmia. During their ICU stay, 34 (14.7\%) patients had ventricular arrhythmias while 5 patients (2.2\%) had complete heart blocks. At the time of last follow-up, 84 (36.4\%), 42 (18.2\%), 29 (12.6\%), and 5 patients (2.2\%) had incomplete right bundle branch block (RBBB), complete $\mathrm{RBBB}, \mathrm{RBBB}$ with left anterior hemi-block and complete heart block, respectively. The results indicate that the group A patients most likely had cardiac arrhythmia during their ICU stay, and at the time of last follow-up $(\mathrm{P}<$ 0.001) while the incidence of cardiac arrhythmia at the operation room was not statistically significant between the two groups $(\mathrm{P}=0.06)$. The mean age and body mass index (BMI) were $53.45 \pm 53.84$ and $15.63 \pm 2.30$, respectively, in patients with cardiac arrhythmia at the time of last follow-up, and were $56.21 \pm 47.83$ and $15.30 \pm 3.89$ in patients with sinus rhythm, respectively. There were no statistical differences in age and BMI between these groups ( $P=0.052$ and 0.77 , respectively).

Complications that were considered included postoperative bleeding, sepsis, neurological accidents, and pulmonary hypertensive (PH) crisis. Among 231 patients, postoperative bleeding and $\mathrm{PH}$ crisis occurred in 5 (2.2\%) and 2 $(0.9 \%)$ patients, respectively. One patient $(0.4 \%)$ in group A died during follow-up because of severe pneumonia. 


\section{Discussion}

Our study has some limitations including the lack of long-term follow-up. Therefore, the incidence of late permanent AV block requiring pacemaker implantation is not defined in our study. However, the follow-up duration was not statistically different between groups.

In conclusion, our study demonstrated that although the prevalence of conduction disorders in both continuous and interrupted suturing for VSD surgical repair is around $1 \%$, it is significantly less common with the interrupted compared to the continuous method.

Ventricular septal defect (VSD) is one of the most common defects requiring surgical intervention $(7,8)$. Lillehei and associates performed the first surgical closure of the VSD in 1955 (9, 10). Several subsequent improvements in surgical repair, including improved techniques in cardiopulmonary bypass, myocardial preservation, anesthesia, and postoperative care, have greatly reduced operative mortality. Complications are rare, but can include residual VSD, conduction disorder, emergent reoperation, neurologic injury, and death $(9,10)$. For infants who undergo surgical closure of VSD, long-term results are similarly positive. Meijboom and associates (11) reported normal growth in all survivors with a good quality of life after more than 10 years postoperatively. Other recent studies report similar outcomes, with the risk of mortality, major morbidity, emergent reoperation, and significant residual VSD of approximately $1 \%$ (10).

Conduction system injury continues to be a leading cause of long-term postoperative cardiac morbidity, especially with the performance of more surgical procedures in increasingly younger patients. Complete heart block has been a serious complication of VSD closure which is associated with an increased risk of late death $(1,12)$. Because of the close anatomic relationship of the atrioventricular node and the bundle of His to the inferoposterior wall, the conduction system is particularly at risk during closure of perimembranous VSDs $(13,14)$. Increasing knowledge of the anatomy of the conduction system has greatly decreased the incidence of intraoperative injury $(2,15,16)$. In fact, numerous studies have reported the absence of complete heart block after VSD closure $(11,17,18)$. Andersen et al. (2) recently reviewed the results of a large series of patients undergoing VSD repair at the Great Ormond Street Hospital for Children during a 26-year period. Based on the results of their study, they suggest that the risk of iatrogenic complete heart block with VSD closure should be less than $1 \%$ and the expected mortality rates for these patients should be approaching $0 \%$.

The results of our study exhibited a higher rate of $\mathrm{CHB}$ compared to that previously reported by Andersen et al (2). The incidence of complete heart block and an operative mortality were $2.2 \%$ and $0.4 \%$, respectively. Furthermore, overall morbidity was minimal, with 9 (3.9\%) patients requiring reoperation for residual VSD, the absence of valve-related complications, and preservation of left ventricular function postoperatively.

Right bundle branch block is a recognized finding after VSD closure, and this was also observed in our study, with 84 (36.4\%) incomplete RBBB, 42 (18.2\%) complete RBBB and 29 (12.6\%) RBBB with left anterior hemi-block cases, respectively. The significance of long-standing right bundle branch block has been debated, and a recent report by Pederson et al. (19) studied the long-term significance of right bundle branch block on left ventricular function after surgical closure of VSD. They noted that right bundle branch block continues to be a common finding after surgical repair, which in long term follow up, does not appear to affect systolic ventricular function but may be associated with diastolic dysfunction. Right bundle branch block after surgical closure of VSD remains a common finding that warrants long term evaluation.

Previous studies have detected potential risk factors for atrioventricular block after surgical repair of VSD. Some studies have suggested an association between surgical heart block and small size, but these were inadequately powered to provide definitive data $(20,21)$. Siehr et al. (22) have demonstrated that patients weighing less than 4 kilograms were at significantly higher risk for surgical AV block. Our results could not find such a difference. Moreover, Anderson et al. (23) has substantiated that VSD location and type of repair were also important in predicting the risk of heart block. They reported that patients with atrioventricular canal repair were more likely to develop postoperative heart block compared to those with isolated VSD and TOF repair. Additionally, the majority of patients with surgical heart block had inlet VSDs. This likely relates to the proximity of the AV node and the posteriorinferior margin of the inlet VSD. Our study demonstrated that the prevalence of inlet VSD was higher in patients with sinus rhythm at the last follow-up (7.8\% versus $11.7 \%$ ), which was not statistically significant $(\mathrm{P}=0.13)$. Malalignment VSDs were detected in $21.1 \%$ of patients with sinus rhythm and $18.7 \%$ of patients with cardiac arrhythmia (P $=0.15)$, respectively; these results were not similar to results from previous studies (2).

Another difference in VSD repair involves the use of either the continuous or interrupted stitch. Tanveer et al. (24) previously compared the incidence of residual VSD after the use of the continuous and interrupted types of stitches in patients with TOF. Their results demonstrated that residual VSD is more common with the continuous compared to the interrupted suturing technique of VSD closure. No postoperative heart blocks were detected in any of their patients (24). Although our results were consistent with theirs while incidence of residual shunt was higher in continuous suture type group than interrupted one $(\mathrm{P}<0.01)$. Residual VSD may result from insufficient intraoperative exposure or suture disruption with patch dehiscence (24-26). Significant residual shunting is most commonly observed in mus- 
cular defects. It has been suggested that trabeculations decrease the visualization of the full extent of the VSD (24). Our results also demonstrated that $67 \%$ ( 6 out of 9) of the moderate residual VSD shunt occurred in either the muscular or inlet type of VSD.

Multivariate analysis on our data resulted in the selection of AVB risk factors including age, height, weight, and BSA at the time of surgery, preoperative treatment, congenital mitral regurgitation, VSD/BSA, suture type, temperature during operation, duration of ICU stay and intubation, postoperative and discharge residual VSD as well as the PR and QRS durations at the time of discharge. There were no statistical differences in these risk factors between continuous and interrupted suture groups except for the PR and QRS durations, respectively, at the time of discharge. Therefore, the differences in the incidence of AVB can be attributed to the type of suturing. This was the first time that type of suturing has been evaluated as a risk factor for AVB.

\section{Authors' Contributions}

Study concept and design: Maziar Gholampour-Dehaki, Hoda Javadikasgari, Asghar Zareh, Solmaz Babaki. Acquisition of data: Maziar Gholampour-Dehaki, Hoda Javadikasgari, Asghar Zareh, Solmaz Babaki. Analysis and interpretation of data: Maziar Gholampour-Dehaki, Hoda Javadikasgari, Asghar Zareh, Solmaz Babaki. Drafting of the manuscript: Maziar Gholampour Dehaki, Hoda Javadikasgari, Asghar Zareh, Solmaz Babaki. Critical revision of the manuscript for important intellectual content: Maziar Gholampour-Dehaki, Hoda Javadikasgari, Asghar Zare, Solmaz Babaki. Statistical analysis: Maziar Gholampour-Dehaki, Hoda Javadikasgari, Asghar Zareh, Solmaz Babaki. Study supervision: Maziar Gholampour-Dehaki, Hoda Javadikasgari, Asghar Zareh, Solmaz Babaki.

\section{References}

1. Moller JH, Patton C, Varco RL, Lillehei CW. Late results (30 to 35 years) after operative closure of isolated ventricular septal defect from 1954 to 1960. Am J Cardiol. 1991;68(15):1491-7.

2. Andersen HO, de Leval MR, Tsang VT, Elliott MJ, Anderson $\mathrm{RH}$, Cook AC. Is complete heart block after surgical closure of ventricular septum defects still an issue? Ann Thorac Surg. 2006;82(3):948-56.

3. Sasson L, Katz MG, Ezri T, Tamir A, Herman A, Bove EL, et al. Indications for tricuspid valve detachment in closure of ventricular septal defect in children. Ann Thorac Surg. 2006;82(3):958-63.

4. Carminati M, Butera G, Chessa M, Drago M, Negura D, Piazza L. Transcatheter closure of congenital ventricular septal defect with Amplatzer septal occluders. Am J Cardiol. 2005;96(12A):52L-8L.

5. Holzer R, de Giovanni J, Walsh KP, Tometzki A, Goh T, Hakim F, et al. Transcatheter closure of perimembranous ventricular septal defects using the amplatzer membranous VSD occluder: immediate and midterm results of an international registry. Catheter Cardiovasc Interv. 2006;68(4):620-8.

6. Alizadeh-Ghavidel A, Nabavi S, Haghjoo M, Toutonchi Z, Mirm- esdagh Y, Javadikasgari $\mathrm{H}$. Amiodarone versus lidocaine for the prevention of reperfusion ventricular fibrillation: A randomized clinical trial. ARYA Atheroscler. 2013;9(6):343-9.

7. Hoffman JIE, Kaplan S. The incidence of congenital heart disease. JAm Coll Cardiol. 2002;39(12):1890-900.

8. Dehaki MG, Ghavidel AA, Omrani G, Javadikasgari H. Long-Term Outcome of Mechanical Pulmonary Valve Replacement in 121 Patients with Congenital Heart Disease. Thorac Cardiovasc Surg. 2014.

9. Lillehei CW, Cohen M, Warden HE, Ziegler NR, Varco RL. The results of direct vision closure of ventricular septal defects in eight patients by means of controlled cross circulation. Surg Gynecol Obstet. 1955;101(4):446-66.

10. Mavroudis C, Backer C, Jacobs J. Ventricular septal defect. Pediatric cardiac surgery. 3 ed. Philadelphia: Mosby; 2003.

11. Meijboom F, Szatmari A, Utens E, Deckers JW, Roelandt JRTC, Bos E, et al. Long-term follow-up after surgical closure of ventricular septal defect in infancy and childhood. J Am Coll Cardiol. 1994;24(5):1358-64.

12. Lillehei CW, Varco RL, Cohen M, Warden HE, Patton C, Moller JH. The First Open-Heart Repairs of Ventricular Septal Defect, Atrioventricular Communis, and Tetralogy of Fallot Using Extracorporeal Circulation by Cross-Circulation: A 30-Year Follow-up. Ann Thorac Surg. 1986;41(1):4-21.

13. Boccanelli A, Wallgren CG, Zetterqvist P. Ventricular Dynamics After Surgical Closure of VSD. Scand Cardiovasc J.1980;14(2):153-7.

14. Tamiya T, Yamashiro T, Matsumoto T, Ogoshi S, Seguchi H. A Histological Study of Surgical Landmarks for the Specialized Atrioventricular Conduction System, with Particular Reference to the Papillary Muscle. Ann Thorac Surg. 1985;40(6):599-613.

15. Truex RC, Bishof JK. Conduction system in human hearts with interventricular septal defects. J Thorac Surg. 1958;35(4):421-39.

16. Milo S, Ho SY, Wilkinson JL, Anderson RH. Surgical anatomy and atrioventricular conduction tissues of hearts with isolated ventricular septal defects. JThorac Cardiovasc Surg. 1980;79(2):244-55.

17. McGrath LB. Methods for repair of simple isolated ventricular septal defect. J Card Surg. 1991;6(1):13-23.

18. Backer CL, Winters RC, Zales VR, Takami H, Muster AJ, Benson DW et al. Restrictive ventricular septal defect: How small is too small to close? Ann Thorac Surg. 1993;56(5):1014-9.

19. Pedersen TA, Andersen NH, Knudsen MR, Christensen TD, Sorensen KE, Hjortdal VE. The effects of surgically induced right bundle branch block on left ventricular function after closure of the ventricular septal defect. Cardiol Young. 2008;18(4):430-6.

20. Tucker EM, Pyles LA, Bass JL, Moller JH. Permanent pacemaker for atrioventricular conduction block after operative repair of perimembranous ventricular septal defect. J Am Coll Cardiol. 2007;50(12):1196-200.

21. Kogon B, Butler H, Kirshbom P, Kanter K, McConnell M. Closure of symptomatic ventricular septal defects: how early is too early? Pediatr Cardiol. 2008;29(1):36-9.

22. Siehr SL, Hanley FL, Reddy VM, Miyake CY, Dubin AM. Incidence and risk factors of complete atrioventricular block after operative ventricular septal defect repair. Congenit Heart Dis. 2014;9(3):211-5.

23. Anderson JB, Czosek RJ, Knilans TK, Meganathan K, Heaton P. Postoperative heart block in children with common forms of congenital heart disease: results from the KID Database. J Cardiovasc Electrophysiol. 2012;23(12):1349-54.

24. Tanveer R, Khan AU, Siddiqi TA, Siddique S, Nasreen A, Salman ur $R$, et al. Continuous versus interrupted technique of ventricular septal defect (VSD) closure in total correction for tetrology of Fallot pertaining to residal VSD. J Pak Med Assoc. 2010;60(4):253-6.

25. Zaman HJ, Cheema MA. The effect of residual ventricular septal defects on early clinical outcome: Initial Experience. J Coll Physicians Surg Pa. 2000;10:325-8.

26. Hennein H, Mosca R, Urcelay G, Crowley D, Bove E. Intermediate results after complete repair of tetralogy of Fallot in neonates. $J$ Thorac Cardiovasc Surg. 1995;109(2):332-44. 